\title{
Understanding obstacles and opportunities for successful market introduction of crop varieties with resistance against major diseases
}

\author{
Edwin Nuijten • Jan de Wit • Leen Janmaat • \\ Annegret Schmitt • Lucius Tamm • \\ Edith T. Lammerts van Bueren
}

Received: 23 June 2017 / Accepted: 15 August 2017 / Published online: 6 September 2017

(C) The Author(s) 2017. This article is an open access publication

\begin{abstract}
Organic agriculture only allows a few "natural' compounds for managing pests and diseases such as copper which is applied as fungicide in apple, grape, potato, and tomato production. But as a heavy metal, copper is under debate in the organic sector. One key strategy to replace copper use is the market introduction of resistant varieties. In this article, key obstacles and opportunities for the introduction of new apple and potato varieties are identified and described. A comparative analysis integrating agricultural, economic,
\end{abstract}

E. Nuijten · J. de Wit $\cdot$ L. Janmaat •

E. T. Lammerts van Bueren

Louis Bolk Institute, Hoofdstraat 24, 3972 LA Driebergen,

The Netherlands

E. Nuijten

e-mail: e.nuijten@louisbolk.nl

L. Janmaat

e-mail: 1.janmaat@louisbolk.nl

A. Schmitt

Julius Kühn-Institut, Federal Research Centre for Cultivated

Plants, Heinrichstr. 243, 64287 Darmstadt, Germany

e-mail: Annegret.Schmitt@julius-kuehn.de

L. Tamm

Research Institute of Organic Agriculture, Ackerstrasse 113,

5070 Frick, Switzerland

e-mail: lucius.tamm@ fibl.org

E. T. Lammerts van Bueren $(\bowtie)$

Plant Sciences Group, Department of Plant Breeding, Wageningen

University and Research, Droevendaalsesteeg 1, 6708

PB Wageningen, The Netherlands

e-mail: edith.lammertsvanbueren@wur.nl cultural, and social perspectives is conducted based on literature review, information on internet, and interviews with key experts, mainly from the organic sector. As a framework for analysis, the concepts of brokerage and the multilevel perspective have been used. The following solution pathways are described: (a) make use of added value of varieties, (b) create demand (pull effects), (c) well-coordinated marketing concepts, (d) new marketing concepts such as the Flavour Group Concept, (e) gradual introduction through shorter chain (when limited funding), and (f) match varieties to food chain styles. Key lessons are the following: (i) there must be an urgent need that develops into a pull factor; (ii) for creating pull factors, it is important to involve others; (iii) a shared language and a common culture between involved stakeholders needs to be developed; (iv) without push factor, no new steps will be realised; (v) new concepts need to fit in existing chain structures; (vi) patience is often important, and (vii) some luck is often crucial.

Keywords Resistance breeding - Market introduction . Agronomic and societal value $\cdot$ Comparative approach . Brokerage $\cdot$ Multilevel perspective

\section{Introduction}

In the organic production of crops such as apple, grape, tomato, and potato, which are susceptible to severe fungal infections, copper is often used as one of the very few 'natural' fungicides permitted in organic agriculture. The 
European project CO-FREE aimed to develop innovative methods, tools, and concepts for the replacement of copper to reduce the use of copper in organic farming systems, as it is considered harmful for the environment (Dagostin et al. 2011). It is shown that it is not easy to minimise copper use by replacement with alternative plant protection products, as they are often less effective than copper-based sprayings itself (Dagostin et al. 2011), causing a major negative economic impact in most production systems (De Wit 2016). Therefore, the introduction of new, resistant varieties is a key strategy to move away from copper-based management of fungal diseases in certain crops. However, previous studies have shown that the introduction of novel varieties often meets substantial obstacles, as retailers' and/or consumers' awareness has to be generated in order to open the market (Tamm et al. 2004; Weibel et al. 2007; Vanloqueren and Baret 2008). Disease resistance is an important trait for farmers but not immediately appealing for traders, retailers, and consumers, as they are hardly aware of the fact that current varieties are not always robust. An explanation is that in general disease resistance has rarely been recognised as one of the important factors in agricultural production chains due to the availability of synthetic pesticides (Vanloqueren and Baret 2008). According to Vanloqueren and Baret (2008), the low priority of disease resistance is the result of a selfreinforcing process with multiple stakeholders, eventually resulting in a lock-in situation. A lock-in situation means that the chain actors lock each other as change of one chain actor requires simultaneous change of the other chain actors. No single approach exists to solve such lock-in situations. Vanloqueren and Baret (2008) also point out that factors that make the introduction of alternative strategies difficult can be summarised as uncertainty, coordination problems, technology immaturity, inflexibility, technology inertia, and path-dependence. To escape from a lock-in situation requires strong exogenous pressure or special efforts from the whole value chain. In some cases, brokerage can be considered an option to develop solutions (Klerkx and Leeuwis 2009). Geels and Schot (2007) have described various scenarios for change from a multilevel perspective.

When it comes to the introduction of new, diseaseresistant varieties of species such as apple and potato, the use of variety names in marketing is an additional complicating factor. Traditionally, apples and potato are sold by their variety names. Hence, much more than for other crops, apple and potato varieties are connected to cultural values. The established variety names are associated with specific taste and/or cooking qualities and therefore play an important role in the marketing, particularly in large anonymous markets dominated by supermarkets. Several studies have shown that in the case of apple, good taste is equally important to freshness for consumers (Péneau et al. 2006; Seppä et al. 2012; Tomala et al. 2009; Weibel et al. 2012). Consumers know that a particular variety has a specific taste and particular uses and will not easily switch to new, unknown varieties. This situation also exists with grapevine and in some European countries also with pear and strawberry.

Hence, it is also needed to consider cultural and societal aspects next to agricultural and market factors in order to understand how to reduce the use of copper in the organic sector. Thus, in order to understand how to improve the success of the introduction of new, diseaseresistant varieties of apple, potato, and grape, in this article, various cases of market introduction of varieties are described and compared from a holistic perspective, looking at agronomic, economic, social, and cultural aspects. As such, reduction of copper use is not just a change in agricultural practice but also needs to be considered a change in societal practices and values. Potential obstacles, key elements, and lessons learned are discussed and summarised.

\section{Material and methods}

A comparative analysis is conducted based on our own case with pilots on market introduction of new late blight-resistant potato cultivars in the Netherlands, our own case with improvement of marketing of new scabresistant apple cultivars in the Netherlands, our own case with the Flavour Group Concept in Switzerland, with three other cases in the Netherlands and France, supported by literature review, product information from internet, and interviews with four experts, mainly from the organic sector. The comparison includes predominantly cases on the introduction of apple varieties with scab resistance, the reason being that the introduction of scab-resistant apple varieties has been going on for several years and is relatively well documented.

The analysis takes a holistic perspective, where the reduction of copper is not only important from an agricultural perspective but also from a societal perspective. As a framework for analysis, the concepts of innovation brokerage (Klerkx and Leeuwis 2009) and the 
multilevel perspective (Geels and Schot 2007) have been used. Innovation is a complex process of interaction among people, technology, knowledge, policy, and the market. Innovation brokers can work at different levels as innovation catalysts, by facilitating interaction and forging connections between various actors. Whereas, innovation brokerage focuses more on the interactions among people and organisations, the multilevel perspective is useful in elucidating interactions between a technology (in our case, disease-resistant varieties), farmers, industry policy, culture, and the market at several levels (Fig. 1).

In the case of potato, the type of late blight resistance (the resistance gene, but also the method of breeding, e.g., genetic engineering or classical breeding, see Lammerts van Bueren et al. 2008) is shaped by various elements, such as science, policy, culture, and the market, that together constitute the dominant socio-technical regime. New innovations may also develop at the niche level (Fig. 1). As the niche level has little or no structure, at this level, innovations can take many different forms and result in very different types of innovations. At the level of the dominant socio-technical regime (mainstream regime), the development of innovations is highly influenced by the main elements of a particular socio-technical regime. The dominant sociotechnical regime is quite stable and may resist change or make small adjustments, but can sometimes change rapidly. Niche innovations are the result of small networks of actors who support novel developments based on different visions. These small networks vary in stability and may change or disappear over time. Depending on societal dynamics, niches may (a) maintain themselves in the margins; (b) deliver innovations to the dominant sociotechnical regime (dominant players can adopt or buy technologies (e.g. new varieties) developed by niche players; (c) become absorbed by the dominant sociotechnological regime (the niche player is bought by a large company that is part of the dominant regime); or (d) disappear. Both the dominant sociotechnological regime and the niche are shaped by the socio-technological context, which consists of

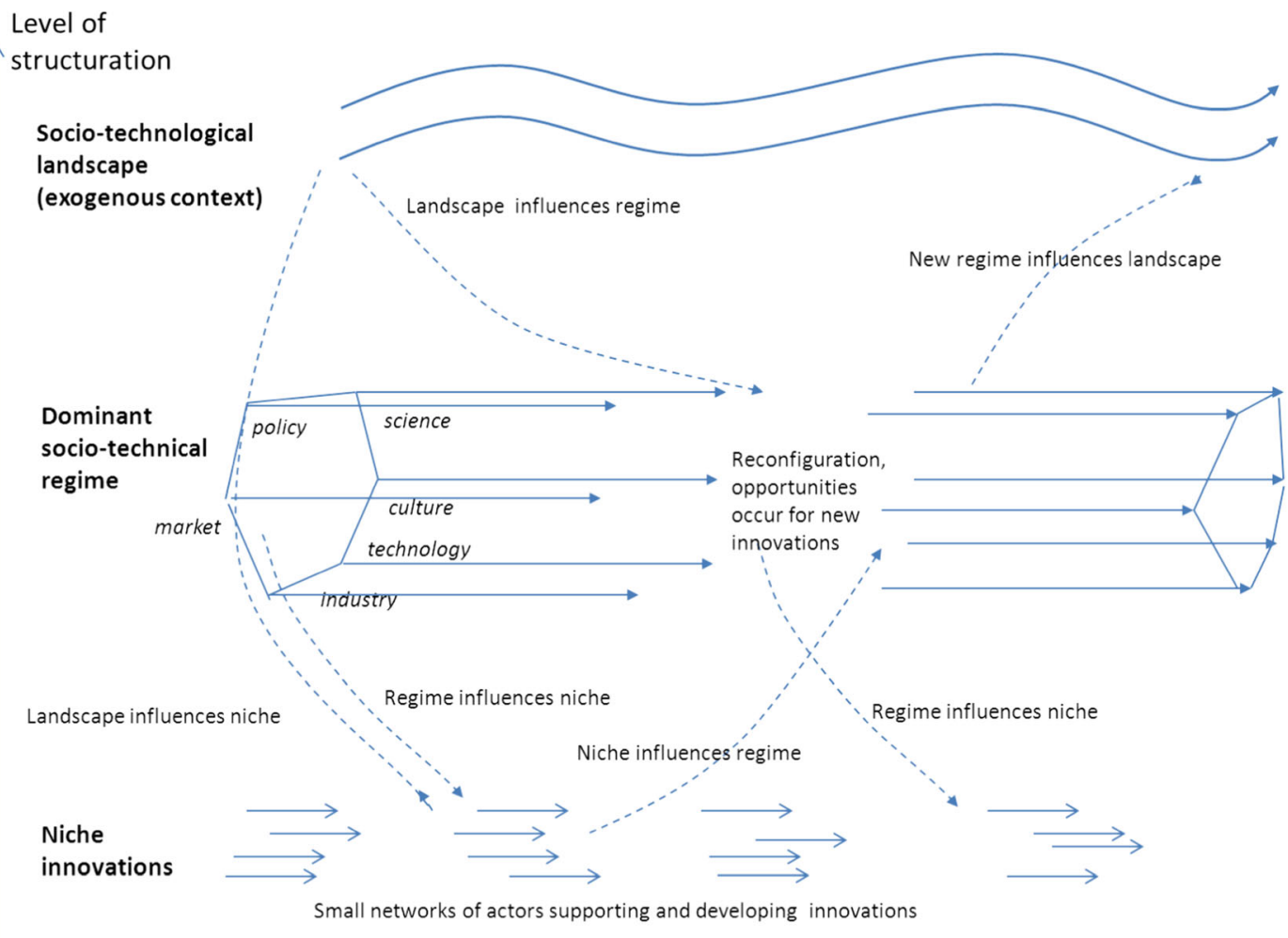

Time

Fig. 1 Dynamics in innovations at various levels according to the multilevel perspective (adapted from Geels and Schot 2007) 
factors that change only gradually, such as climate, soil texture, or demography.

\section{Results}

Current status of crop breeding and the value chain: the context

\section{Plant breeding}

First, we want to briefly describe the plant-breeding activities from the perspective of the framework of the multilevel perspective. In the case of breeding for late blight resistance for potato, or scab resistance for apple, the resistance pre-breeding is mostly done by various research institutes which are part of the dominant sociotechnical regime. The new resistant genotypes are subsequently used in breeding by both breeding companies (part of the dominant socio-technical regime) and individual famer breeders (niche level) (Almekinders et al. 2014). These two categories may have different breeding strategies for organic agriculture. The large breeding companies aim to develop varieties that also do well in conventional farming to expand the area of sales per variety, whereas niche players primarily, though not exclusively, aim for organic agriculture. Through the development of new networks, which is important for the viability of the niche-players, organic farmer breeders often have innovative farming strategies and subsequent variety trait priorities different from those of conventional dominant socio-technical regime (Lammerts van Bueren et al. 2008). Both categories may adopt new ideas from each other potentially leading to the development of joint approaches or new ideas (Nuijten et al. 2012). However, such as mentioned by Sansavini (2009), dominant players also adopt measures to keep control of the market and prevent niche players from entering the market.

\section{The value chain: apple and scab resistance}

Since the 1950s, hundreds of apple varieties have been gradually replaced by a few high-yielding varieties with good taste, such as 'Golden Delicious', 'Jonagold', or 'Elstar'. These varieties have in common that they are highly susceptible to apple scab (Venturia inaequalis). With the introduction of novel synthetic fungicides from the 1950s onwards, scab as one of the most important apple diseases could be controlled by fungicides, and resistance was no longer important. Hence, the new high-yielding varieties have replaced the old varieties with relatively good scab resistance, but relatively low yields. Over several decades, consumers and traders have become very accustomed to these varieties, their names, and their qualities. Trading and cultivating a limited number of varieties over larger areas is easier and more economical. For the consumer, to be able to quickly identify and buy the apple variety you know in the supermarket is a matter of convenience. Hence, customers and traders are reluctant to change their preference. For that reason up to today, organic growers supplying the main markets have to grow mainstream varieties such as 'Elstar', even though these are difficult to grow under organic conditions, not only due to their disease susceptibility but in some countries also because of their growth habit requiring more hand pruning. Another specific problem for organic apple orchards is that these intensive orchards were designed for conventional production, and hence after converting to organic management, lack stabilising factors for pests and diseases (Tamm et al. 2004). It is important to mention that disease and pest resistance breeding may only be part of the solution.

The introduction of new apple varieties is a complicated challenge, even more so for scab-resistant apple varieties. Every year, some 20 new apple (scab resistant and susceptible) varieties are introduced in Europe and 50 varieties worldwide. However, only few of these newly introduced varieties become cultivated at a large scale. About $70 \%$ of all apple production in Europe comes from eight varieties: 'Golden Delicious', 'Red Delicious', 'Gala', 'Jonagold', 'Elstar', 'Braeburn', 'Fuji', and ‘Granny Smith' (Sansavini 2009). One key factor for the limited uptake of new varieties is that the nursery sector holds the licences for variety multiplication and is in a key position in the marketing of new varieties by setting the prices for new trees (Sansavini 2009). With an increase in use of technology in tree multiplication, a larger share of the rights to variety multiplication is held by few big business groups that can control the market (Sansavini 2009). Another factor that slows down the replacement of susceptible varieties is the high investment needed for replanting an orchard (Tamm et al. 2004). Moreover, as the first scab-resistant varieties did not have good eating and storage qualities, consumer acceptance was low. Today, scab-resistant varieties with good taste are available, such as 'Topaz' 
and 'Santana' (Tomala et al. 2009; Weibel et al. 2012), although varieties with good storage ability are still few.

From the above, it becomes clear that various different chain actors (breeders, nurserymen, growers, traders, and consumers) directly or indirectly hinder the successful introduction of new varieties. Even though the uptake of disease-resistant varieties can support the reduction of fungicides and hence can be considered environment friendly, various actors in the dominant socio-technical regime have no direct benefit or interest with a successful uptake:

- Traders rather prefer large quantities of a limited number of varieties.

- Consumers have certain taste preferences and have become used to particular products (varieties) and are reluctant to take up new varieties.

- Government policy is to leave the development of new innovations more and more to the market.

Given these circumstances, it is not surprising that scab-resistant varieties are not widely planted in Europe. The fact that the dominant varieties are very susceptible to scab is not enough reason for market players to replace them (Weibel et al. 2007). For other crops, like grapes, similar issues have to be solved to make introduction of mildew-resistant grape varieties successful. In any case, investments are only justified if the resistance traits are durable, e.g. if the resistance of varieties is not overcome by virulent pathogen populations (which is currently the case with apple scab).

However, change from within a dominant market system (e.g. a dominant 'socio-technical regime', see Fig. 1) does happen. For example, in the Netherlands, traders for the organic market are gradually shifting position and become more interested in varieties other than 'Elstar' (Jansonius, pers. communication 2013).

\section{The value chain: potato and late blight resistance}

For potato, similar to apple, the number of traders and packers has reduced since the 1980s (Rademakers and McKnight 1998). In comparison to apple, the case of potato varieties with late blight resistance (Phytophthora infestans) differs in a number of aspects. Being an annual crop, trying new potato varieties means less of a risk for farmers compared to apple varieties which are planted for at least $10-15$ years. The first potato varieties with new late blight resistance genes, e.g. 'Bionica' and 'Sarpo
Mira', entered the market in 2007 in the Netherlands, after a long period of lacking resistant varieties. Only since then other new late blight resistant varieties entered the market, e.g. 'Alouette', 'Carolus', 'Connect', and 'Vitabella'. These varieties can be very important to organic farmers, as they enable farmers to have higher yield, improved yield security, and imply less need to spray with compounds such as copper. However, the uptake of these varieties even by the organic market has been slow, because chain partners and consumers are not familiar with these new varieties. One important reason is that they have unfamiliar combinations of taste, flesh colour, and cooking properties. Another complicating factor is that, for example in the Netherlands, the choice of the assortment of varieties offered to the supermarkets is largely made by a few potato packers as a new variety often means that an existing variety needs to be discarded to create shelf space. If a breeding company that does the breeding and marketing of new varieties has real interest in the introduction of a new resistant variety (for example 'Carolus'), the breeding company needs to convince the packer and market introduction is then relatively easy. On the other hand, if a company does not see a large enough potential market for a variety (as was the case with 'Bionica', see case $\mathrm{d}$ further on), this may complicate the introduction of a new variety for the organic sector. For conventional breeders, the development and introduction of new varieties will be more profitable if the new variety fits in different markets, e.g. both organic and conventional. However, at the moment, only a few varieties are suited for both organic and conventional farming. Also, in some countries, the producers of seed potatoes prefer a small set of varieties to produce seed tubers of. Hence, an important issue is to develop strategies to improve the adoption of new potato varieties with late blight resistance which are important for the yield security for growers but less so for traders (the smaller number of varieties, the more efficient their work) and consumers (as they are used to the 'common' varieties).

Possible solution pathways

In the last decades, several factors have made the introduction of new apple varieties rather difficult, for both scab resistant varieties and other varieties for the conventional market (Sansavini 2009). In other words, a lock-in situation has gradually developed over time (Vanloqueren and Baret 2008). To change this situation, different solutions may be possible. In this section, 
various cases of successful market introduction of resistant varieties are analysed.

Case a: link variety names to added value: the apple 'Santana'

When a variety has added values that are recognised by all stakeholders in the food chain (growers, traders, and consumers), then there would be not so many obstacles to get a variety accepted. However, sometimes an important added value is only apparent or recognised in a later stage such as was the case with 'Santana'.

The variety Santana stems from a cross between the varieties Elstar and Priscilla, from a breeding program in 1978 of the Plant Breeding Department of Wageningen University and Research. This variety entered the market in 1996 with mainly scab resistance as the added value for growers. The flavour was comparable to a much appreciated variety Elstar. However, in the following years, unexpected quality problems during storage in the shops arose, e.g. susceptibility for rotting at the core. Only a few growers were able to grow this variety and continued its production for organic retailers. Some 10 years later, by accident, a Dutch organic grower discovered that 'Santana' had a low allergenic effect (De Stentor 2006; Van der Maas 2011). More than half of consumers with apple allergy can digest this variety without allergic reactions which was a unique event worldwide and created much media attention. This information was used to promote this variety and created a new added value for the market and increased the demand also of non-allergic consumers. This event might have contributed to easier market acceptance of other new scab resistant varieties such as Topaz and Evelina (Van der Maas 2011).

One key lesson is some added values like scab resistance are purposely bred for, while other added values can be discovered by coincidence. Another key lesson is that it can take time before added values are found.

\section{Case b: well-coordinated marketing concept in combination with a new brand name, the apple variety Juliet $\mathbb{B}$}

Club varieties are trademarked varieties. The production is controlled and only exclusively grown by a limited number of growers on a limited acreage and sold for a higher price compared to the common varieties on the market (Laurent, personal communication 2013). Well- designed marketing in combination with the concept of a club variety made this variety attractive to consumers and stimulated market demand.

The market introduction of this apple variety Juliet ${ }^{\circledR}$ has its own history and was not smooth from the beginning. It originated from a US breeding program in the 1970s for scab resistance (PRI 2012). It was tested in 1995 under its original name Co-op 43 (Korban et al. 2003). As its quality traits were not as one could expect from the pedigree, it was suggested to be a result of outcrossing and thus a lucky chance (Goffreda et al. 1995). In 1999 in France, the variety was released as Juliet ${ }^{\circledR}$. The performance in tests under conventional farming conditions was disappointing with respect to storability and flavour. Nevertheless, the licence for Europe was bought by a French nurseryman who developed the variety club 'Les Amis de Juliet ${ }^{\circledR}$ ' together with a nursery tree grower and a technician (Pommejuliet 2012). Due to positive collaboration between a number of important stakeholders in the value chain, this French variety club had a quick start and enabled Juliet ${ }^{\circledR}$ to be produced successfully since 2005 . The production of Juliet ${ }^{\circledR}$ has gradually increased from $1800 \mathrm{t}$ (2011) to $8500 \mathrm{t}$ in 2016 (Freshplaza 2012, 2014, 2016). Key elements of the successful club concept were the following: (i) exclusive marketing, (ii) limited production in France among 80 organic growers, (iii) controlled distribution by a limited number of packaging stations (6) in France, (iv) offering a broad series of products (e.g. various packaging, desserts, juices, etc.), (v) special promotion in trade shows, in retail, press through internet, and games, and (vi) creating opportunities to join as a friend of 'Juliet@'.

Key lesson is that marketing is as important as breeding a good variety, and creating a strong brand is a strong marketing tool.

Case c: new marketing concepts to by-pass the variety names: the flavour group concept

Often organic value chains tend to stick to varieties that have established their names in the conventional markets. Franco Weibel (organic research institute FiBL in Switzerland) searched for a way to market new apple varieties better adapted to organic farming and not known in the conventional market. Another obstacle he had to deal with was the fact that many of these new varieties covered a too small volume to be really interesting for the Swiss organic market. The basic idea 
was not to promote the varieties by their names but by their specific flavour in three groups.

This Flavour Group Concept refraining from using the apple variety names was completely against the traditional marketing concept (Weibel, pers. communication in 2012). There was quite some effort needed to make this concept understandable for the involved Coop produce buyers. Once understood in marketing terms, the Flavour Group Concept rapidly developed. The varieties were put into three flavour groups indicated with colours on the labels: (a) yellow: mild to sweet; (b) red: spicy, rather tart; and (c) green: predominantly tart (Weibel and Leder 2006). Although consumers appreciate also appearance and texture, taste is considered most important (Seppä et al. 2012; Tomala et al. 2009). Supermarkets normally require year-round offer of the same varieties and require large quantities of apples. To overcome this requirement, the new Flavour Group Concept has the advantage that new varieties with similar taste, but each produced in limited quantities can be grouped and marketed together in a flavour group and in total meet the volume requirements. This offers a way to more easily introduce new varieties in the market (Weibel and Leder 2006). Easier introduction of new resistant varieties in the market is not only important for Swiss organic growers but is also a stimulus for Swiss breeders. Today, in Switzerland, some $40 \%$ of the organically produced apples come from scab resistant varieties compared to merely $10 \%$ in Germany.

Key factors for this concept were the following: (1) Franco Weibel from FiBL was prepared to make continuous efforts to convince traders and supermarkets; (2) at that time, the supermarket chain Coop was aiming to improve its profile and competitiveness; (3) the number of scab resistant apple varieties adapted to Swiss growing conditions increased around that time; (4) in the same period, the Swiss government changed its agricultural policy from supporting quantity to quality; this stimulated apple producers to convert to organic management including new scab resistant varieties; and (5) Switzerland supports its domestic apple production by apple import tariffs.

A positive result of these efforts is that consumers have accepted the Flavour Group Concept (Weibel and Leder 2006). The label colours have become a common language for retailers and consumers. At first, packagers assumed the new way of working would result in more work, but meanwhile appreciate the flexibility of the system. Since 2000, the Flavour Group Concept is also applied to apples derived from conventional, integrated apple production systems. In 2002, the other Swiss main supermarket chain Migros introduced a slightly different version with two flavour groups. Also for potato, both supermarkets followed along this line of thinking by applying various cooking groups, instead of promoting variety names.

Key lesson is if at several levels conditions are right, a new marketing concept can be successful.

Case d: translate weak traits into unique selling points: the case of potato Niek's Witte

Late blight resistance is an important trait for organic potato producers. But this characteristic is not valued by Dutch traders and consumers when it comes with white flesh of the potato as was the case with variety Bionica. In the Dutch culture, traders and consumers are not used to white-fleshed potatoes and prefer light yellow-fleshed potatoes. Thus, the introduction of the potato variety Bionica in 2007 was not easy. This variety was jointly bred by a commercial breeder and a biodynamic farmer breeder Niek Vos. Vos tried various Dutch markets: boxschemes and small and larger regional supermarkets. The sales in the supermarket were not successful. However, the response to an organic box-scheme chain which added the story behind this variety in the weekly newsletter to the consumers was high and overall positive. Many Dutch organic consumers did not mind the white flesh and sympathised with the story behind this variety, especially the aspect of being a farmer-bred variety was appreciated.

To stimulate more sales with limited funding, it was decided to build on this positive experience and emphasise the personal image and on-farm origin by replacing the variety name Bionica by the brand name Niek's Witte (meaning Niek's White). Also, special packaging was designed by adding a picture of the father (Niek) and his son on the paper bag with the story of the breeding process at the backside. With this approach, the weak point (not always appreciated white flesh colour) was turned into a strong point (underlining the uniqueness of the product). The variety currently has a small but steady position in the Dutch organic market, and in addition is produced for organic markets in a few other countries where white-fleshed potatoes are more common, such as in England and Sweden. 
Key lesson is disliked traits can be neutralised or even turned into strong points, in that way increasing the use value of a variety.

Case e: shorter chain, gradual introduction: the case of summer apple variety Collina

A low-cost, gradual approach is another option for the introduction of new varieties. This approach eventually leads to the successful introduction of the apple variety Collina, bred by the Dutch farmer breeder Mart Vandewall. In 1986, he started to make crosses out of curiosity (VanderWall 2012). Several progenies showed healthy leaves, good scab resistance, and good yield (Vandewall 2012). One of his crosses included the same parents as for the variety Santana but lead to a different selection that was later introduced as 'Collina'. In the testing phase, it stood out because of its earliness, taste, and appearance. He asked various apple growers and breeders to assess the flavour. Collina joined official variety testings at three locations (the Netherlands, Belgium, and Germany). This testing process lasted over 4-5 years with positive evaluations. It was lucky to be added, last minute, to a tasting panel at an international meeting in Belgium, and it was very positively received. After this event, the farmer breeder decided to obtain breeder's rights for this new variety.

Mart Vandewall pictured the entire process of including growers and breeders to evaluate the flavour as an oil patch that gradually spread (Vandewall 2012). In this period, a nursery man got seriously interested. Together, they decided to try to introduce Collina and share the financial risks. It was agreed that in the first years, trees of this variety would only be sold to organic growers, and only thereafter to conventional producers. Another positive event was that media started to write about Collina and praise it as a typical summer apple with very good flavour. Meanwhile, Vandewall continued to stimulate other growers to try Collina, expanding continuously the oil patch continued. He considered this important for the adoption of the new variety. The first adopters have now also replanted their first fields again with Collina.

To summarise, the most important elements of the success of Collina were its good flavour, the positive testing outcomes by several research stations, and the continuously shared evaluation with other growers. As Vandewall is also an apple grower himself, communication among colleagues was easy, and they helped to spread the positive news. Next to having a good taste, the variety provides added value for various chain players such as the following: for growers, improved scab resistance and a relative good storability, for consumers, the low-allergenic trait similar to Santana, and for organic shops, the replacement of imported apples during the summer period and hence providing a shorter and cheaper trade route. For supermarkets, 'Collina' has two disadvantages: it is partially susceptible to bi-annual bearing affecting delivering stable quantities but also the period of harvesting may vary about 1 week between years making predictions of delivery date to retailers complex (Vandewall 2012).

Key lesson is that with good networking, and limited resources, it is possible to introduce new varieties.

Case f: brokerage: food chain styles and apple varieties in the Netherlands

From 2000 to 2004, a project was conducted to stimulate the sales of organic apples in supermarkets and health food shops in the Netherlands. The Louis Bolk Institute (LBI) organised several meetings, bringing farmers to supermarkets, and vice versa, in order to increase the understanding for each other's priorities and bottlenecks (Jansonius et al. 2004). In 2004 and 2005, the focus was on optimising the quality and sale in shops of the scab resistant variety Topaz (Jansonius and Zanen 2005a, b). In these case studies, LBI functioned as a broker as described by Klerkx and Leeuwis (2009). As each apple variety has particular storage behaviour in the growers' storehouse and on the shelves in the shops, good communication between growers and buyers is very important with the introduction of a new variety (Jansonius and Zanen 2005a). A general lesson was that although chain players learned to better understand each other's positions, it proved difficult to translate that into better cooperation in practice (Jansonius et al. 2004). This applied particularly to the chains with smaller supermarkets. The chains with large supermarkets were more successful, because these large supermarkets have the capacity for a better organisation to maintain the quality of the apples in the shops (Jansonius et al. 2004). This means a better sale of the apples, which is an advantage to the growers, despite the very high standards set by the 
supermarkets for buying the produce from the growers.

Simultaneously, a study was conducted to better understand the underlying mechanisms for successful introduction of new apple varieties, analysing different apple production and value chain styles (Van der Meulen et al. 2004). The most important styles were identified as the 'nice maker' and the 'independent' (Table 1). 'Nice maker'-supermarkets tend to set high standards for their products. Consequently, apple growers will only plant new varieties if they are sure that the supermarket will buy the produce. And when a supermarket decides to take up a new variety, they demand big quantities to be sold over a substantial period of time. In this way, growers depend to a large extent on the decision-making of the big supermarkets. It implies less room for decisions by growers on the one hand, but on the other hand, a guarantee of sales (Jansonius et al. 2004). The analysis showed that smaller supermarkets are more flexible and often set lower quality demands, but the downside is that they do not always have the means to maintain a certain level of quality of the produce during shelf life (Jansonius et al. 2004). 'Independent growers' have more freedom to decide which varieties to grow. Because of their strong relationships with wholesale and organic shops, they can more easily sell their products of new varieties. Joint efforts for promotion in organic shops are an important tool to substantially increase sales of new varieties (Jansonius and Zanen 2005b). 'Box fillers' are more flexible in variety choice, because they have close connections with their costumers and guaranteed sales of their produce due to the subscribed consumers. However, the volume box-scheme producers aim for per variety is often small, because they grow a diversity of varieties and because the sales through box-scheme systems is often limited to some 200-250 families. The 'niche workers' often concentrate on traditional and rare varieties. They will only switch to new varieties if they have a clear added value for the costumers.

Key lesson is that good interaction between value chain players depends on good knowledge exchange and on sharing economic and cultural values. Organic shops seem easier channels to introduce new scabresistant varieties to consumers. Large supermarkets allow the cultivation of large areas of scab resistant varieties.

\section{Discussion}

Here, we describe and discuss various perspectives on how to create change in the introduction of new varieties with important disease resistance, based on the analysis of the case studies described in this paper. Varieties need to meet criteria important to a range of value chain players. A new variety trait beneficial to farmers does not automatically mean a successful introduction on the market, as the variety also needs to meet criteria important for retailers and consumers.

\section{Basic principles of variety introduction}

For a better understanding of possible solutions, it is important to understand some basic principles of variety introduction. If a new variety is registered, it does not automatically imply it will be cultivated and marketed. Successful introduction of new varieties depends on a number of technological and socio-economic factors, and the interaction of these factors (Nuijten et al. 2013).

One important factor is the availability of other good varieties. If there are many other good and

Table 1 Summary of chain styles, their characteristics and the varieties mostly cultivated by growers, based on Van der Meulen et al. (2004)

\begin{tabular}{|c|c|c|c|c|}
\hline Chain style & Keyword & $\begin{array}{l}\text { Product } \\
\text { characteristic }\end{array}$ & Sale via & Varieties \\
\hline Nice makers & $\begin{array}{l}\text { Efficiency, } \\
\text { quantity, price }\end{array}$ & $\begin{array}{l}\text { Shiny, uniform, outer } \\
\text { quality, low price }\end{array}$ & $\begin{array}{l}\text { Supermarket large scale, } \\
\text { closed chain }\end{array}$ & $\begin{array}{l}\text { Mostly common/few new: } \\
\text { Santana, Topaz }\end{array}$ \\
\hline $\begin{array}{l}\text { Independent } \\
\text { growers }\end{array}$ & Trust/flexible & Quality (outer and inner) & $\begin{array}{l}\text { Whole sale/organics shops; } \\
\text { medium scale, open chain }\end{array}$ & $\begin{array}{l}\text { Diverse, common and new: } \\
\text { Santana, Topaz, Collina }\end{array}$ \\
\hline Box fillers & $\begin{array}{l}\text { Guarantee of } \\
\text { sale/convenience }\end{array}$ & The unusual/seasonal product & $\begin{array}{l}\text { Box scheme system, various other } \\
\text { channels, small scale }\end{array}$ & Various, common and new \\
\hline Niche workers & $\begin{array}{l}\text { Diversity/varieties/ } \\
\text { history }\end{array}$ & Taste, quality, local & Various small scale & Rare varieties \\
\hline
\end{tabular}


competing varieties in a specific sales segment, it will be more difficult to get a new (e.g. resistant) variety being accepted by both farmers and consumers. A common feature of all the cases described in this paper is that the usual pathway for variety introduction does not work, or not good enough, because what is good for a grower is not automatically appreciated or recognised by traders, supermarkets, and/or consumers. The 'highway principle' can be used to illustrate the following:

- Easy traffic: easy to get on the highway

- Busy traffic: difficult to get on the highway and find a gap

- Success rate decreases, level of luck increases

- In case of traffic yam: use b-roads

- Good knowledge of the chain network important

- The shorter the chain, the easier the introduction

- Shared culture makes communication easier

Another important factor is that every variety has strengths and weaknesses. A good variety needs to meet at least the minimum threshold for a range of traits. But today, meeting the minimum criteria is not good enough. Successful introduction depends on the added value of a variety compared to current varieties for all players in a production chain. For example: scab resistance in apple is very important for growers to reduce costs, but not in the first place for consumers. The first generation of scab resistant apple varieties, for example the varieties Prima and Priscilla, offered to the nursery industry from 1970 to 1988 (Crosby et al. 1992) lacked in taste and were not accepted by the market. Instead, they were used as crossing parents in further breeding. For example, Priscilla is the parent of scab resistant varieties such as Santana and Collina. In general, developing varieties that have added value for all chain players is difficult, because there is often a trade-off between traits or they are not easy to combine such as scab resistance, yield, storability, and taste.

\section{Dominant market players}

Sometimes, it is argued that dominant players in a value chain can force change, as they have the resources and influence to create change (Hekkert et al. 2007). Case c on the Flavour Group Concept seems a good example, as the role of the supermarket Coop has been very crucial. However, in case c, the role of the researcher Weibel was identified as equally crucial besides other beneficial circumstances. In the other cases, however, no dominant market player was involved or difficult to indicate. This may also be logical, as often dominant chain players have no or too little interest in changing the existing situation if there is no real necessity for them. This partly explains the lock-in situation in the adoption of disease-resistant wheat varieties in conventional farming (Vanloqueren and Baret 2008). The cases described here deal mostly with rather small markets: the organic market. Perhaps, such markets are often too small for dominant chain players to be interested in and to force change.

Innovation brokerage

Weibel, who played a crucial role in case c, can be considered an example of an innovation broker. New innovations can be catalysed through innovation brokers (Klerkx and Leeuwis 2009). Innovation brokers can be persons or organisations that bring together the chain actors and improve interactions between these chain actors. Facilitating acceptance for new varieties needs constant effort over an extended period of time. Some cases described in this paper do have innovation brokers (cases c, d, and f). For an innovation broker to have impact, the innovation broker needs to have detailed knowledge of both the technology (in this case, disease-resistant varieties) and the value chain. One may also argue that some of the key players in cases a, b, and e also played, to some extent, the role of innovation broker. Reasoning in this way means that good communication and facilitation (important elements of brokerage) are important to make new innovations successful. It should also be noted, however, that the modes of communication were very different, such as in cases $\mathrm{c}$ and $\mathrm{e}$.

A comparison based on the multilevel perspective

All the cases show various levels of interplay within the value chain and with the external circumstances. In Table 2, the case studies are organised according to transition pathway as described by Geels and Schot (2007). The varieties Santana and Niek's Witte have not drastically changed the dominant regime but can be considered to have paved the way for other new varieties for both crops. The case of Collina can be considered a niche innovation, not having had much impact on the dominant 
Table 2 Classification of the cases in transition pathways as described by Geels and Schot (2007) and whether innovation brokers (see Klerkx and Leeuwis 2009) were involved

\begin{tabular}{|c|c|c|c|}
\hline Transition pathway & Cases & $\begin{array}{l}\text { Innovation } \\
\text { broker }\end{array}$ & Short description of the change \\
\hline \multirow[t]{2}{*}{ No transformation } & Collina (case e) & No & $\begin{array}{l}\text { A typical niche innovation, very different approach, } \\
\text { but no clear effect on the dominant regime }\end{array}$ \\
\hline & Brokerage (case f) & Yes & Limited change at all levels \\
\hline \multirow[t]{2}{*}{ Transformation } & Santana (case a) & No & $\begin{array}{l}\text { These niche innovations can be considered } \\
\text { front runners that changed regime practices and, } \\
\text { to some extent, paved the way for similar varieties }\end{array}$ \\
\hline & Niek’s Witte (case d) & Yes & \\
\hline Technological substitution & - & Not applicable & $\begin{array}{l}\text { No examples yet (otherwise, this paper was probably } \\
\text { not written) }\end{array}$ \\
\hline Reconfiguration & Club varieties (case b) & No & $\begin{array}{l}\text { A combination of old and new elements results in } \\
\text { a modification of the socio-technical regime at } \\
\text { several levels }\end{array}$ \\
\hline De-alignment and re-alignment & Flavour group concept (case c) & Yes & $\begin{array}{l}\text { Simultaneously with a set of scab-resistant varieties } \\
\text { changes occurred at the socio-technical regime } \\
\text { and the landscape level (agricultural law) }\end{array}$ \\
\hline
\end{tabular}

socio-technical regime. The use of club varieties seems a rather successful approach, but apparently only feasible in certain contexts. For scab resistant apple varieties, it seems that the socio-technological landscape in France is more favourable for club varieties compared to the Netherlands, for example. However, the concept of club varieties is successfully applied in the Netherlands in other contexts (for example, the conventionally grown Tasty Tom tomato). Perhaps, the lesson is that small details can make the difference between success or failure. In the case of the Flavour Group Concept that lead to a reconfiguration of the value chain, many details at several levels where at the right mode at the same time to make success possible. The case of Julliet ${ }^{\circledR}$ may also be an example of starting up an initiative at the right time (e.g. a window of opportunity).

The Flavour Group Concept has, so far, been very successful only in Switzerland. Some elements have been copied in other countries, but not the complete concept. In the Netherlands, several factors contributed to the lack of success of the Flavour Group Concept to promote scab-resistant varieties for the organic market. To make the concept functioning, several varieties per flavour group need to be available together making up a certain quantity to avoid gaps in delivery, which is still not the case in the Netherlands. Until recently, it was already difficult to get organic apples as such sold in supermarkets in the Netherlands (Jansonius et al. 2004). According to some, the variety Santana was important to stimulate the introduction of new apple varieties cultivated organically, particularly into supermarkets (Van der Maas 2011). Furthermore, no supermarket in the Netherlands has an economic and profiling interest similar to Coop. Hence, no pull factor nor chain organiser exists. In addition, not enough budget was available to push the concept over a longer period of time. Another likely factor is that Dutch culture is also different from Swiss culture. Dutch people do not bother that much to eat locally grown food, nor do they have that much of an interest in organically produced food as Swiss people do (see Willer and Lernoud 2016).

Furthermore, a comparison of apples and grapes indicates that sometimes also the socio-technological landscape, e.g. laws and policy, needs to change to make successful introduction possible (Weibel, personal communication 2012). In Switzerland, import tariffs for apple make investments in apple cultivation more feasible, whereas for grapes, no import tariffs exist making grape cultivation and investments in grape cultivation less lucrative.

The complex interplay of niches and dominant socio-technical regimes

An important lesson is that innovation does not necessarily happen only at the niche level or the dominant regime. Often, the innovation and the innovation path is a more or less complex interplay between niche and dominant 
regime and can take several years or even decades. This is illustrated by the apple variety Santana, which was developed as part of the dominant regime but remained unsuccessful until its low allergenic properties were discovered. During this unsuccessful period, it was maintained by a dedicated farmer (as a niche variety) who by chance observed an important new trait (added value). Only after that, it became a success and part of the dominant regime again.

The apple variety Collina is another example of the complex interplay of the niche level and the dominant regime. It can be considered a niche innovation, independently developed by a farmer breeder. However, without knowing or meeting the right people of the dominant regime, Collina would not have become a registered variety.

The above cases suggest that successful development and introduction of resistant varieties occurs mostly through the dominant regime. In some cases, resistant varieties are developed in niches in interaction with the dominant socio-technical regime.

\section{Shared economic interest and cultural values}

To have good cooperation in the chain, shared values are important. These values have economic and cultural aspects. Shared values seem to have developed relatively easily in the case of 'Les Amis de Juliet@'. An aspect contributing to this development might have been that there was a demand by growers for a chain like Juliet@. For club varieties, the nursery sector has an important coordinating role (Sansavini 2009). In such chains, the economic aspects, or economic values, are crucial. In the Netherlands, in the early 2000s, cooperation of organic apple growers improved with the big supermarkets but not with the smaller supermarkets (Jansonius et al. 2004). The reason for this is the economic scale. The reason for successful cooperation between some organic shops and some organic apple growers is that they share cultural values (Van der Meulen et al. 2004). As such, it appeared that organic shops play a limited role in the introduction of scab-resistant varieties because of their relatively limited sales, but seem important to keep multiple varieties in play. So, the strength of supermarkets is to make a success of a few varieties and the strength of niche players (organic shops and box fillers) is to maintain newly introduced varieties that are not immediately widely adopted (like the apple Santana). This suggests that the various value chains have different valuable properties when it comes to the introduction of new disease-resistant varieties.

Ingredients for successful variety introduction

Based on the described cases, a number of solutions for potential obstacles (Box 1) and key lessons (Box 2) are identified. Introduction of new varieties is not easy, but four important issues can be recognised.

1) Added value: in the first place, successful introduction of resistant varieties requires that these varieties have to be good in many aspects: variety introduction is easier if there is clear added value for all chain players. To optimise variety introduction and recognise added values for involved

Box 1 Solutions for potential obstacles

For each of the reported case studies, crucial aspects of the strategies and potential obstacles can be observed.

- Link variety names to added value (see case a)

- The standards for breeding are already high and will only become higher. Creating added value is very difficult and sometimes more a result of luck.

- Often needs to be combined with other marketing strategies.

- Well-coordinated marketing concept in combination with a new brand name (see case b):

- It requires a good organisation and funding to support introduction and coordination within the chain.

- Innovative marketing concepts (see case c):

- It requires a long period of continuous organisational and financial support and commitment to convince all chain players (to become pull factors).

- It requires a large number of varieties with different qualities.

- Transform weak traits into unique selling points (see case d).

- Requires out-of-the-box thinking.

- Introduction via boxes fillers and organic shops, potentially followed by upscaling to supermarkets.

- Gradual route for introducing new varieties (when limited funding) (see case e):

- Requires a good informal network

- The introduction/testing via boxes fillers and organic shops, followed by upscaling to supermarkets depends on traits (added value) of a variety and their importance in the market

- Brokerage: improving communication between chain players or matching varieties to food chain styles (see case f):

- Shared culture or a dominant chain player is needed for effective communication

- Varieties can have traits that are more or less important for specific chain styles 
Box 2: Key lessons learned

With the different cases on apple and potato varieties, various lessons become visible. These lessons are particularly useful when you are experiencing problems with variety introduction or in a locked-in situation (when all chain players seem to be stuck in a specific chain model).

The main key-lessons are the following:

- There must be a recognised need - a pull factor: for successful cooperation, all players need to be interested, together creating pull factors. The more pull factors, the more likely an initiative will succeed (all cases).

- To create pull factors, it is important to involve others: there are two options: a dominant player becomes a big pull factor (case b), or many small players together create a pull factor (case d).

- A shared language among chain players and common culture is necessary: different players in the chain may speak different 'languages'/jargon. It is not always easy to understand each other's jargon (case c).

- Without push factor, no new steps will be realised: for new concepts, a continuous push over a long period is needed (all cases).

- New concepts need to fit in existing structures: the appropriate economic and political context is needed (case b and $\mathrm{c}$ ).

- Patience is often important: case studies a and c suggest that various chain players need several years to adapt.

- Some luck is often crucial: in all cases luck was important, in various. In case a, it showed most clearly, where, by chance, and added value was discovered.

chain players, it might be beneficial to involve traders, supermarkets, and other chain players in early phases of variety testing (Weibel and Leder 2006; Nuijten and Lammerts van Bueren 2016).

2) Brokerage: as communication between, and added value for, different chain players is crucial, it is important that some person can act as an intermediate and/or chain organiser.

3) Multiple or specific strategies: depending on the context, a particular marketing strategy can help. Combinations of strategies can strengthen each other, but awareness of conflicting strategies is important: each value chain in each specific sociotechnical landscape has its own characteristics and requirements.

4) In case of lock-in ('traffic jams'): develop innovative concepts: for example, to by-pass the hindrance of variety names, the Flavour Group Concept proved to be a strategy that facilitates the introduction of new varieties in a structural way, as it replaces the variety names with more general qualities. 'Product of the month/week/day' — strategies are slightly similar innovative concepts which can facilitate the introduction of new varieties, of which insufficient quantities are available for a general introduction, without replacing the variety name as a quality standard.

The potential for other alternatives

There are several options for further adapting existing approaches for market introduction. The described cases have in common that they mostly focus on utilitarian values. An important question is whether including normative or ethical values may help clarify a need for change. For example, in a case study on maintaining diversity in hot pepper in Bolivia, consumers considered maintaining diversity a more important argument than taste for paying a higher price (Garcia-Yi 2014). In fact, 'organic product chains' itself are an approach to include normative or ethical values in market decisions. It is important to realise that each approach for market introduction needs to be tailor-made to specific contexts. Further development of organisational models for successful market introduction is necessary to increase the cultivation of crop varieties with resistance against major diseases, as they contribute to more sustainable organic and conventional farming systems.

Acknowledgements This paper is based on the research conducted in the frame of the international project: Innovative strategies for copper-free low input and organic farming systems (COFREE). This project has received funding from the European Union's Seventh Framework Programme for research, technological development, and demonstration under grant agreement no 289497.

\section{Compliance with ethical standards}

Conflict of interest The authors declare that there are no conflicts of interest.

Open Access This article is distributed under the terms of the Creative Commons Attribution 4.0 International License (http:// creativecommons.org/licenses/by/4.0/), which permits unrestricted use, distribution, and reproduction in any medium, provided you give appropriate credit to the original author(s) and the source, provide a link to the Creative Commons license, and indicate if changes were made. 


\section{References}

Almekinders CJM, Mertens L, van Loon JP, Lammerts van Bueren ET (2014) Potato breeding in the Netherlands: a successful participatory model with collaboration between farmers and commercial breeders. Food Security 6:515-524

Crosby JA, Janick J, Pecknold PC, Korban SS, O'Connon PA, Ries SM, Goffreda J, Voordeckers A (1992) Breeding apples for scab resistance: 1945-1990. Fruit Varieties Journal 46:145-166

Dagostin S, Schärer H-J, Pertot I, Tamm L (2011) Are there alternatives to copper for controlling grapevine downy mildew in organic viticulture? Crop Prot 30:776-788

De Stentor (2006) Loftrompet over Santana zonder Santana. De Stentor, 23 June 2006, available at http://www.destentor. nl/regio/noordoostpolder/loftrompet-over-santana-zondersantana-1.2489581. Accessed 14 Apr 2017

De Wit J (2016) Socio-economic impact assessment of copper-free production systems and strategies. Report D9.2 COFREE-project. Louis Bolk Institute, Driebergen, The Netherlands. available at http://www.co-free.eu/images/RESULTS/Projectreports/co-free-socio-economic-impact-assessment-Del-9-2 LBI-def-final-web.pdf. Accessed 14 Apr 2017

Freshplaza (2012) Juliet organic apples blossom out of France. Freshplaza, 10/29/2012. available at http://www.freshplaza. com/news detail.asp?id=88264, visited August 2017

Freshplaza (2014) Production area for Juliet apples to increase. Freshplaza 11/19/2014. Available at http://www.freshplaza. com/article/131292/Production-area-for-Juliet-apples-toincrease, visited 14 Apr 2017

Freshplaza (2016) Juliet organic apple gains popularity. Freshplaza 10/10/2016. Available at http:/www.freshplaza. us/article/6103/Juliet-organic-apple-gains-popularity, visited 14 Apr 2017

Garcia-Yi J (2014) Market-based instruments for the conservation of underutilized crops: in store experimental auction of native chili products in Bolivia. Sustainability 6:7768-7786

Geels FW, Schot J (2007) Typology of sociotechnical transition pathways. Res Policy 36:399-417

Goffreda J, Voordeckers A, Korban SS, Ries SM, Janick J (1995) Co-op 39 to 44: Six disease-resistant apple selections released for advanced testing. New Jersey A.E.S. of Rutgers Univ. Res. Rpt. R-12001-2-95. See https://hort.purdue. edu/newcrop/pri/bibliog.html

Hekkert MP, Suurs RAA, Negro SO, Kuhlmann S, Smits RE (2007) Functions of innovation systems: a new approach for analysing technological change. Technological Forecasting Societal Change 74:413-432

Jansonius PJ, Zanen M (2005a) Kwaliteit van topaz in het winkelschap. Resultaten van de winkelmonitor 2004-2005 in het kader van het project 'Appels van stand' shelf life quality of topaz. Results of the shop monitor 2004-2005. Louis Bolk Institute, Driebergen 18

Jansonius PJ, Zanen M (2005b) Topaz afzetten in de natuurvoedingswinkel. Ervaringen uit de pilotketen 2004-2005 (selling topaz in specialised organic food stores. Experiences from the pilots 2004-2005). Louis Bolk Instituut, Driebergen p. 16

Jansonius PJ, ZanenM, Bloksma JR (2004) Kwaliteit van biologisch geteelde appelen in de keten: Resultaten van monitoring en ketengesprekken binnen project 'Appels van
Stand'. (Quality of organically produced apples in the value chain. Results of monitoring and chain actor discussions within the project 'Apples of Class'). Louis Bolk Institute, Driebergen, The Netherlands. 42 p. Available at http://www. louisbolk.org/downloads/1412.pdf. Accessed 14 Apr 2017

Klerkx L, Leeuwis C (2009) Establishment and embedding of innovation brokers at different innovation system levels: insights from the Dutch agricultural sector. Technol Forecast Soc Chang 76:849-860

Korban SS, Goffreda JC, Janick J (2003) Co-op 43 (Juliet $^{\mathrm{TM}}$ ) apple. Hortic Sci 38:144-145

Lammerts van Bueren ET, Tiemens-Hulscher M, Struik PC (2008) Cisgenesis does not solve the late blight problem of organic potato production: alternative breeding strategies. Potato Res 51:89-99

Nuijten E, Lammerts van Bueren ET (2016) Key elements for collaborative breeding models for organic markets in Europe. In: Davis K (ed) Organic seed growers conference proceedings. February 4-6, 2016, Corvallis, OR. Organic Seed Alliance, Port Townsend, pp 47-52

Nuijten E, Janmaat L, Lammerts van Bueren ET (2012) Nieuwe wegen voor de veredeling van gewassen voor kleine markten: Sleutelelementen voor vruchtbare samenwerking in de keten. Report no 2012-003 LbP. Louis Bolk Instituut, Driebergen p. 34

Nuijten E, Temudo M, Richards P, Okry F, Teeken B, Mokuwa A, Struik PC (2013) Towards a new approach for understanding interactions of technology with environment and society in small-scale rice farming. In: Wopereis MCS, Johnson DE, Ahmadi N, Tollens E, Jalloh A (eds) Realizing Africa's rice promise. CABI Publishing, Wallingford, pp 355-366

Péneau S, Hoehn E, Roth H-R, Escher F, Nuessli J (2006) Importance and consumer perception of freshness of apples. Food Qual Prefer 17:9-19

Pomme-juliet (2012) Association "Les Amis de Juliet". Montayral, France. http://www.pomme-juliet.com, visited 14 April 2017

PRI (2012) Disease resistant apple breeding program. http://www. hort.purdue.edu/newcrop/pri/, visited 14 April 2017

Rademakers MFL, McKnight PJ (1998) Concentration and interfirm co-operation within the Dutch potato supply chain. Supply Chain Manag: Int J 3(4):203-213

Sansavini S (2009) Horticulture in Europe: from history to innovation. Acta Hortic 817:43-58

Seppä L, Railio J, Mononen R, Tahvonen R, Tuorila H (2012) From profiles to practice: communicating the sensory characteristics of apples to the wider audience through simplified descriptive profiles. Food Sci Technol 47:46-55

Tamm L, Häseli A, Fuchs JG, Weibel FP, Wyss E (2004) Organic fruit production in humid climates of Europe: bottlenecks and new approaches in disease and pest control. Acta Hortic 638: 333-339

Tomala K, Baryłko-Pikielna N, Jankowski P, Jeziorek K, WasiakZys G (2009) Acceptability of scab-resistant versus conventional apple cultivars by Polish adult and young consumers. J Sci Food Agric 89:1035-1045

Van der Maas MP (2011) Santana en Topaz: schurftresistent en succesvol. In: Wijnands FG, van Keulen H (eds) bioKennis Innovatie Magazine. bioKennis, Wageningen, pp 46-47

Van der Meulen HS, Jansonius PJ, Jonker L, Van Teeffelen W, Zanen M (2004) Ketenstijlen in de biologische appelsector 
(in Dutch). Rapport LF77. Louis Bolk Instituut, Driebergen, The Netherlands. 19pp.

VanderWall (2012) Bijzondere rassen (in Dutch). Puurvanderwall homepage, see http://www.puurvandewall.nl/bijzondererassen,36.html, visited 14 April 2017

Vanloqueren G, Baret PV (2008) Why are ecological, low-input, multi-resistant wheat cultivars slow to develop commercially? A Belgian agricultural 'lock-in' case study. Ecol Econ 66: 436-466

Weibel FP, Leder A (2006) Experiences with the Swiss (organic) method how to introduce new apple varieties into retail market: flavour group concept and variety team. The compact fruit tree $39: 1-5$
Weibel FP, Tamm L, Wyss E, Daniel C, Häseli A, Suter F (2007) Organic fruit production in Europe: successes in production and marketing in the last decade, perspectives and challenges for the future development. Acta Hortic 737:163-172

Weibel FP, Kruczynska D, Konopacka D (2012) Consumer preference of apple cultivars suited for organic production and which factors influence the buying decision. Acta Hortic 933: 645-652

Willer H, Lernoud J (2016) The world of organic agriculture. Statistics and emerging trends 2016. Research Institute for Organic Agriculture (FiBL), Frick, and IFOAM-Organics International, Bonn 